\title{
Application of immunofluorescence assay and nested polymerase chain reaction for query fever diagnosis in animal handlers of Puducherry, South India, and phylogenetic analysis based on IS1111 repetitive gene element
}

\author{
Jothimani Pradeep ${ }^{1}$, Selvaraj Stephen ${ }^{1}$, Balakrishnan Sangeetha ${ }^{1}$, Prabakar Xavier Antony ${ }^{2}$, S. Amsaveni ${ }^{2}$ and \\ Pratheesh Pooja ${ }^{3}$
}

1. Department of Microbiology, Mahatma Gandhi Medical College and Research Institute, Sri Balaji Vidyapeeth (Deemed to be University), Puducherry, India; 2. Department of Veterinary Microbiology, Rajiv Gandhi Institute of Veterinary Education and Research, Puducherry, India; 3. Central Interdisciplinary Research Facility, Mahatma Gandhi Medical College and Research Institute, Sri Balaji Vidyapeeth (Deemed to be University), Puducherry, India.

Corresponding author: Selvaraj Stephen, e-mail: stephens4950@gmail.com

Co-authors: JP: drpradeepmicro@gmail.com, BS: sangeethabvs@gmail.com, PXA: pxantony@gmail.com, SA: amsvet1982@gmail.com, PP: poojapratheesh@gmail.com

Received: 23-07-2019, Accepted: 09-10-2019, Published online: 13-11-2019

doi: www.doi.org/10.14202/vetworld.2019.1769-1774 How to cite this article: Pradeep J, Stephen S, Sangeetha B, Antony PX, Amsaveni S, Pooja P (2019) Application of immunofluorescence assay and nested polymerase chain reaction for query fever diagnosis in animal handlers of Puducherry, South India, and phylogenetic analysis based on IS1111 repetitive gene element, Veterinary World, 12(11): 1769-1774.

\begin{abstract}
Background and Aim: Diagnosis of query fever (QF) is mostly done on the basis of serological/molecular tests, due to the stringent requirement of biosafety level-3 containment facilities for isolating Coxiella burnetii in culture. QF is an important zoonosis and is considered to be an occupational hazard to livestock handlers. This report describes our study on the serological as well as molecular evidence of QF in animal handlers from Puducherry and surrounding Tamil Nadu, from where, to the best of our knowledge, no such reports are available so far.
\end{abstract}

Materials and Methods: Seventy-five animal handlers were recruited, comprising veterinarians, slaughterhouse workers, butchers, and animal attendants of various government veterinary clinics from Puducherry and surrounding areas of Tamil Nadu state. QF serology was performed to identify Phase I and Phase II immunoglobulin G antibodies to C. burnetii. Nested polymerase chain reaction (N-PCR) was carried out to detect $C$. burnetii DNA in buffy coat samples by targeting IS1111 gene element. N-PCR-positive samples were sequenced and phylogenetic analysis was performed using MEGA software version 10.0 .

Results: A total of 21 animal handlers (28.1\%) were positive for either serology or PCR. PCR alone was positive in $10(13.4 \%)$, only serology was positive in $8(10.7 \%)$, and both serology and PCR were positive in three samples $(4.0 \%)$. GenBank accession numbers were obtained for 13 N-PCR-positive samples (MG548608-MG548620). Six of our study sequences showed close similarity with the reference isolates from Bengaluru, Colombia, Brazil, France, and Iran.

Conclusion: A significant percentage of QF positivity in animal handlers of this part of South India, Puducherry, warrants a prospective study with follow-up of a large number of this occupational group.

Keywords: Coxiella burnetii, immunofluorescence assay immunoglobulin G, Q fever in Puducherry, query fever nested polymerase chain reaction, zoonosis.

\section{Introduction}

Query fever (QF) is an important emerging zoonotic disease worldwide [1,2] but does not come under the list of notifiable diseases in India and several other countries [3]. It is caused by Coxiella burnetii and is an occupational disease to animal handlers such as veterinarians, butchers, and slaughterhouse workers in abattoirs/animal farms, but mostly, they are asymptomatic. The disease can be transmitted to humans by

Copyright: Pradeep, et al. Open Access. This article is distributed under the terms of the Creative Commons Attribution 4.0 International License (http://creativecommons.org/licenses/ by/4.0/), which permits unrestricted use, distribution, and reproduction in any medium, provided you give appropriate credit to the original author(s) and the source, provide a link to the Creative Commons license, and indicate if changes were made. The Creative Commons Public Domain Dedication waiver (http:// creativecommons.org/publicdomain/zero/1.0/) applies to the data made available in this article, unless otherwise stated. either ingestion of unpasteurized milk or inhalation of abortion products of domestic animals [2,4-11].

Only a few reports of $C$. burnetii isolation from aborted tissues and blood samples of livestock have been published in Indian literature [12-15]. Since isolation in culture is confined only to reference laboratories due to biosafety concerns, serology/polymerase chain reaction (PCR) is considered to be the preferred test [2]. Several studies from India have employed serological tests for the detection of C. burnetii antibodies in blood samples of domestic animals as well as humans [3,14,16-19]. In India, few researchers performed PCR for confirming this zoonosis $[3,12,15,17]$ and the phylogenetic tree was analyzed on the basis of IS1111 gene target [13]. To the best of our knowledge, QF in this occupational category has not been reported in South India so far. 
The objective of this preliminary research was to study the prevalence of QF in animal handlers of Puducherry by applying the gold standard serological test immunofluorescence assay (IFA) and the molecular diagnosis by performing nested PCR (N-PCR).

\section{Materials and Methods}

\section{Ethical approval}

This study was conducted in a tertiary care teaching hospital, Puducherry, with approval from the Institution Human Ethics Committee.

\section{Study area}

This study was conducted in the department of microbiology of a tertiary care superspecialty teaching hospital and genomics and proteomics department of central research laboratory at Puducherry during January 2015-March 2018.

\section{Processing of blood samples}

Five $\mathrm{mL}$ of blood was collected from each of 75 animal handlers during January 2016-December 2017. Serum samples and DNA extracts from buffy coats were preserved at $-80^{\circ} \mathrm{C}$. Batch testing by N-PCR and IFA was performed after an interval of 6-12 months.

\section{IFA}

QG-120 (Phase I + II) IFA (C. burnetii IFA Fuller Laboratories, California, USA) was performed according to the manufacturer's instructions. For immunoglobulin G (IgG) IFA, patients' serum samples were diluted 1:16 using IgG Sample Diluent which contains goat serum in phosphate-buffered saline (PBS). Further dilutions were carried out in PBS for positive samples. Slides were incubated at $37^{\circ} \mathrm{C}$ for $30 \mathrm{~min}$ in a humidity chamber. Positive and negative controls were included daily during each run. Slides were removed from the incubator and gently washed with PBS, dipped in PBS for 5 min and kept in sterile distilled water to remove the residues and allowed to dry. Ten $\mu 1$ of conjugate, which comprises purified DyLight 488-labeled goat anti-human IgG (heavy chain) with bovine serum albumin and Evans' blue counterstain was added to the wells and incubated in the dark for $30 \mathrm{~min}$. Slides were gently rinsed with PBS for 3 times and allowed to dry. After the final wash, the slides were mounted with the mounting medium and read with $400 \times$, at $390 \mathrm{~nm}$ using Primo Star iLED fluorescent microscope (Carl Zeiss MicroImaging, GmbH, Gottingen, Germany). Figure-1a shows apple-green fluorescence in a red background for positive samples and Figure- $1 \mathrm{~b}$ without any green fluorescence. According to the kit, significant titer for IgG Phase I is $\geq 1: 16$ and for IgG Phase II, it is $\geq 1: 256$. However, we took the cutoff titers for Phase-II/Phase-I IgG $\geq 1: 128$ which were considered positive for QF as per CDC criterion [1].

\section{DNA extraction}

The genomic DNA was extracted from the buffy coats using QIAGEN Blood Mini Kit (QIAGEN, Germany). The procedure was carried out as per
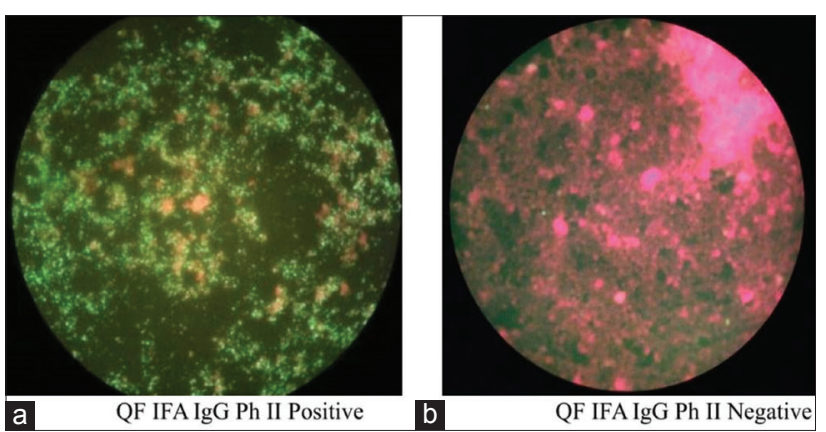

Figure-1: Results show the presence of query fever Phase II immunoglobulin $\mathrm{G}$ antibodies in $a$ and but absent in $b$.

the manufacturer's instructions. The purity of extracted DNA samples was checked by Eppendorf BioSpectrometer $^{\circledR}$ basic (Eppendorf, India). The genomic DNA was aliquoted and stored at $-80^{\circ} \mathrm{C}$ until further use.

\section{N-PCR}

N-PCR was carried out targeting IS1111 transposon repetitive gene element with primers developed by Lorenz et al. [20]. N-PCR primers were standardized using gradient PCR and the procedure was performed.

\section{N-PCR amplification protocol}

Both N-PCR amplifications were carried out in $25 \mu \mathrm{l}$ of reaction mixture with $12.5 \mu \mathrm{l} \times 2$ Taq DNA Polymerase PCR kit (Ampliqon), $1 \mu \mathrm{l}$ of forward primer and reverse primer each, $2 \mu 1$ template DNA, and $8.5 \mu \mathrm{l}$ molecular grade distilled water. The first round amplified products were used as a template for the second amplification. Briefly, the cyclic conditions for the first amplification were carried out using outer primers (Trans 1 and Trans 2) with initial denaturation at $95^{\circ} \mathrm{C}$ for $8 \mathrm{~min}$ followed by 35 cycles of denaturation $95^{\circ} \mathrm{C}$ for $30 \mathrm{~s}$, annealing at $63^{\circ} \mathrm{C}$ for $40 \mathrm{~s}$, and the last cycle extended for final extension at $72^{\circ} \mathrm{C}$ for $5 \mathrm{~min}$. The second amplification was carried out using inner primers (Trans 3 and Trans 4), which was similar to the first amplification except in the annealing temperature at $61^{\circ} \mathrm{C}$ for $40 \mathrm{~s}$ (instead of $63^{\circ} \mathrm{C}$ ). Details of the primers are as follows:

Trans 1: 5'-TATGTATCCACCGTAGCCAGTC-3', Trans 2: 5'-CCCAACAACACCTCCTTATTC-3', Trans 3: 5'-GTAACGATGCGCAGGCGAT-3', and Trans 4: 5'-CCACCGCTTCGCTCGCTA-3'.

The first set of amplification for outer (Trans1 and Trans 2) primers was observed at $687 \mathrm{bp}$ and the second amplification for inner primers (Trans 3 and Trans 4) was observed at $243 \mathrm{bp}$.

N-PCR was carried out using Veriti Dx 96-well Thermal Cycler, Applied Biosystems (Thermo Scientific). The amplified products of amplicon size were visualized at $243 \mathrm{bp}$ in $2.0 \%$ agarose gel electrophoresis with ethidium bromide solution. N-PCR-positive samples (243 bp) were purified using QIAquick PCR Purification kit (Qiagen, Germany). Unidirectional gene sequencing was done by Eurofins 
Genomics India Pvt. Ltd., Bengaluru, India. These sequences were aligned with MultAlin software and submitted to the GenBank, NCBI database. The phylogenetic tree was constructed using MEGA software version 10.0 (Temple University, USA) by maximum likelihood method [21,22].

\section{Statistical analysis}

Mean \pm standard deviation with $95 \%$ confidence interval for the age of animal handlers was calculated using GraphPad QuickCalcs software, USA. Sensitivity, specificity, positive predictive value (PPV), and negative predictive value (NPV) for N-PCR were calculated with MedCalc software, Belgium, keeping IFA as the reference.

\section{Results}

Animal handlers' age ranged from 18 to 70 years and mean \pm SD was $35.8 \pm 13.9$ years with $95 \%$ confidence interval of 32.7-39.1 years. Results of serology and N-PCR are presented in Table-1. Among $21(28 \%)$ animal handlers with serological and/or molecular evidence of QF, PCR alone was positive only in $10(13.4 \%)$, (Figure-2), only serology was positive in $8(10.7 \%)$, and both PCR and serology were

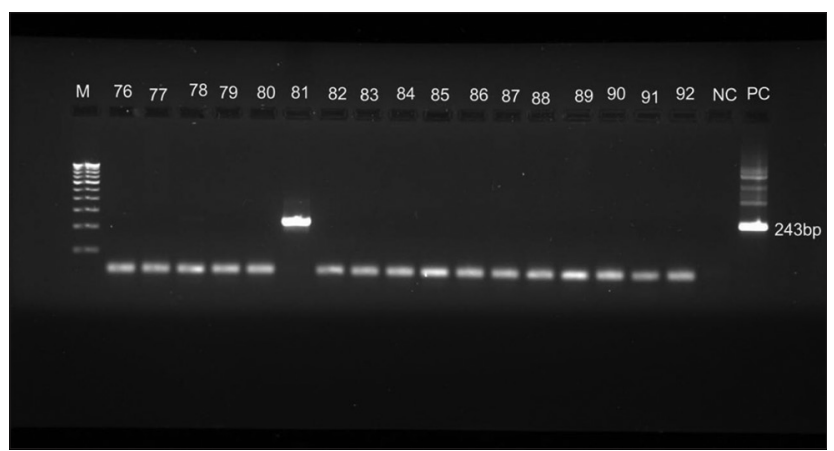

Figure-2: Query fever animal handlers as evidenced by nested polymerase chain reaction for IS1111gene. M - 100 bp DNA marker; Samples 76-80 and 81-92 were negative and sample 81 is positive for Coxiella burnetii DNA; NC: Negative control; PC: Positive control amplified at $243 \mathrm{bp}$. positive in three samples (4\%). Remaining $54(72 \%)$ were negative for both serology and PCR. Sensitivity, specificity, PPV, and NPV of N-PCR against IFA were $27.3 \%, 84.4 \%, 23.1 \%$, and $87.1 \%$, respectively. Gene sequencing was carried out for 13 samples in Eurofins, Bengaluru. Thirteen sequences were deposited in NCBI database and GenBank accession numbers were published (MG548608-MG548620). Phylogenetic analysis was made in IS1111 gene and shows that the six study sequences (AH25, AH28, $\mathrm{AH} 49, \mathrm{AH} 48, \mathrm{AH} 13$, and $\mathrm{AH} 14)$ strongly form a cluster with the reference strains KY372400.1 (Colombia), KT867377.1 (Brazil), KP719165.1 (Iran), LN999998.1 (Bengaluru), LK937696.1 (France), and HG825990.3 (France). Within the clusters, the five isolates (AH10, AH47, $\mathrm{AH} 29, \mathrm{AH} 32$, and $\mathrm{AH} 33$ ) form a subclade and supported by a bootstrap value of $35 \%$ and $87 \%$, respectively (Figure-3). Only one isolate (AH34) showed similarity with the reference isolate KP645185.1 from Brazil.

\section{Discussion}

Our study has identified evidence of QF in 21 of 75 animal handlers (28\%) by IFA and/or PCR. According to CDC criteria, 13 N-PCR-positive samples may be considered as "laboratory-confirmed" QF cases [1]. Seven, in this group, had significant single IFA titers of Phase II $\operatorname{IgG} \geq 1: 128$ and one with Phase I IgG titer of 1:256. These eight seropositive cases belong to the CDC category of "laboratory supportive" QF. CDC does not recommend Phase II Immunoglobulin $\mathrm{M}(\mathrm{IgM})$ testing for acute $\mathrm{QF}$ since IgM may persist for up to 1 year and non-specific (giving false positives) [1]. In this context, Jager et al. [23] recommended a cutoff IFA titer $\geq 1: 32$ for all the four classes of antibodies.

Altogether, 21 animal handlers (28\%) had occupational exposure to and tested positive for $C$. burnetii. Blood samples were tested 6-12 months after collection. DNA deterioration in some samples might have occurred due to the delayed testing and thus,

Table-1: QF IFA IgG Phase I/II and/or N-PCR positivity among animal handlers $(n=75)$.

\begin{tabular}{|c|c|c|c|c|}
\hline \multirow[t]{2}{*}{ S. No. } & \multicolumn{2}{|c|}{ QF IFA IgG positivity } & \multirow{2}{*}{$\begin{array}{l}\text { N-PCR positivity } \\
\text { (IS1111 gene) }\end{array}$} & \multirow[t]{2}{*}{ Occupation } \\
\hline & Phase I titer & Phase II titer & & \\
\hline 1. & $1: 256$ & $1: 128$ & Negative & Animal attendant \\
\hline 2. & $1: 128$ & $1: 512$ & + & Animal attendant \\
\hline 3. & $1: 128$ & $1: 512$ & + & Butcher \\
\hline 4. & $1: 64$ & $1: 256$ & Negative & Butcher \\
\hline 5. & $1: 128$ & $1: 256$ & Negative & Butcher \\
\hline 6. & $1: 128$ & $1: 512$ & Negative & Animal attendant \\
\hline 7. & $1: 128$ & $1: 256$ & Negative & Animal attendant \\
\hline 8. & $1: 64$ & $1: 512$ & Negative & Animal attendant \\
\hline 9. & $1: 256$ & $1: 128$ & + & Butcher \\
\hline 10. & $1: 256$ & $1: 512$ & Negative & Butcher \\
\hline 11. & $1: 64$ & $1: 256$ & Negative & Farmer \\
\hline $12-21$ & Negative & Negative & Positive & Animal handlers \\
\hline $22-75$ & Negative & Negative & Negative & Animal handlers \\
\hline
\end{tabular}

$\mathrm{N}-\mathrm{PCR}=$ Nested polymerase chain reaction, QF IFA IgG=Query fever immunofluorescence assay immunoglobulin $\mathrm{G}, \mathrm{N}-\mathrm{PCR}=$ Nested polymerase chain reaction 


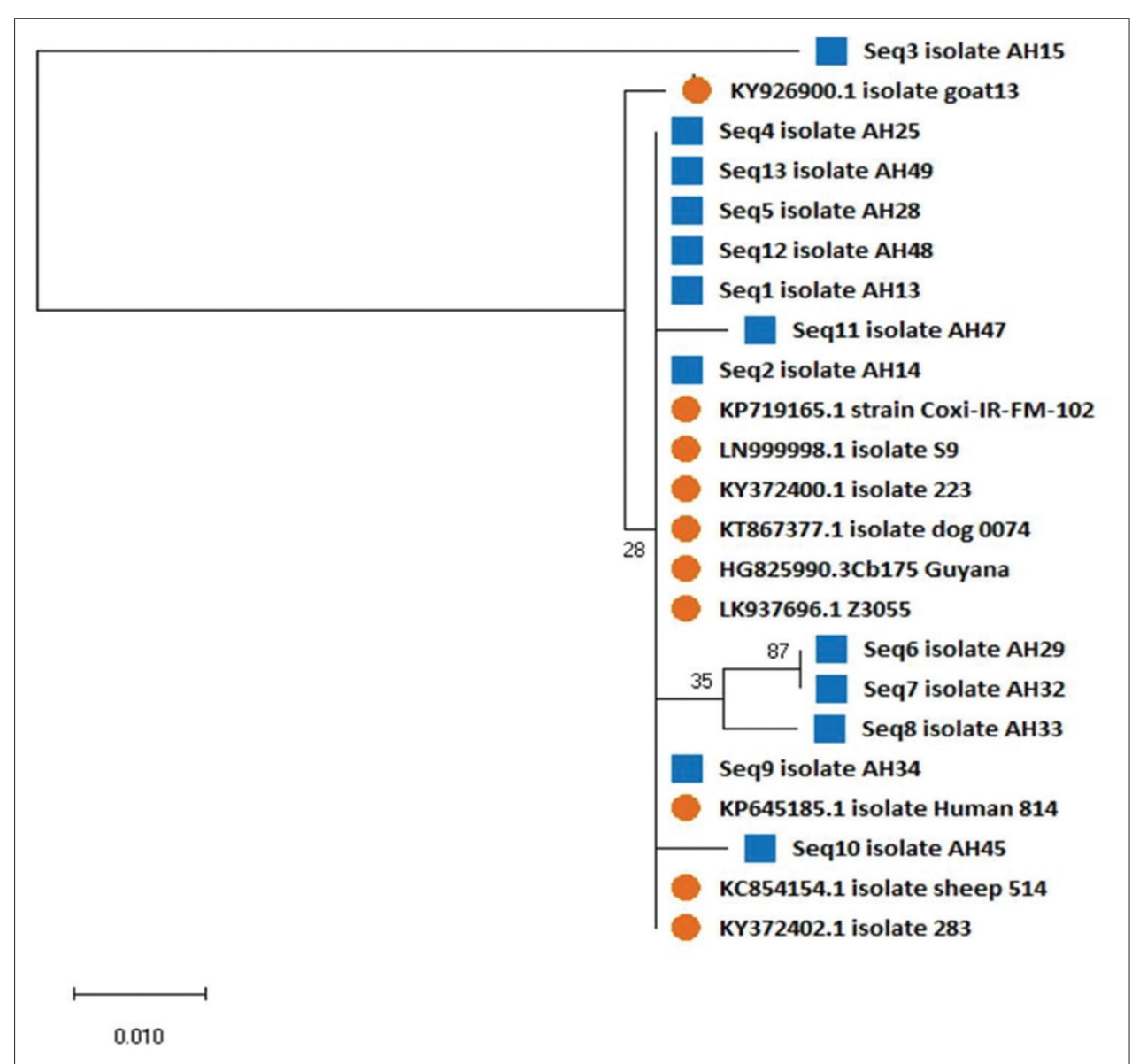

Figure-3: Molecular phylogenetic analysis of IS1111 gene among animal handlers. The evolutionary history was inferred using the maximum likelihood method based on the Tamura-Nei model [24]. Phylogenetic tree was constructed using MEGA software version 10.0 by maximum likelihood method. Blue color indicates our study isolates and orange indicates reference strains from the other isolates.

PCR positivity could perhaps be more than what we obtained. This scenario of a significant percentage of animal handlers (28\%) giving evidence of prior exposure to $C$. burnetii is in contrast to our earlier experience of a low coxiellosis seroprevalence of $0.9 \%$, $1.1 \%, 5.6 \%$, and $1.85 \%$ in cattle, buffaloes, goat, and sheep, respectively [15]. It is known that seropositive animals need not necessarily shed the organism in their secretions/excretions. Conversely, seronegative animals can still harbor C. burnetii. Whitney et al. [6] reported 22.2\% seroprevalence of QF among US veterinarians. Khalili et al. [4] reported a very high $68 \%$ seropositivity among Iranian slaughterhouse workers. Wielders et al. [7] from the Netherlands observed that $36 \%$ of veterinarians had Phase I IgG antibodies $(\geq 1: 1024)$ and considered as possible chronic QF. According to Szymanska-Czerwinska et al. [5] from Poland, $31.1 \%$ of the farmworkers were positive for IFA (Phase I and/or II) IgG. Park et al. [9] reported $9.3 \%$ of $C$. burnetii infection among workers in cattle slaughterhouse. Significance was observed among C. burnetii infection and carcass evisceration workers in South Korea. Seroprevalence of C. burnetii was estimated in $35.6 \%$ cattle farmers and farm residents of Northeastern Provinces and Inner Mongolia region of China [10]. In Afghanistan, a cross-sectional study was conducted by Akbarian et al. [11] and reported that $63.9 \%$ of QF seropositivity was observed among householders with their animals in the villages of Herat Province. By seroprevalence alone, $14.7 \%$ of our animal handlers were positive for $\mathrm{QF}$.

Sensitivity and specificity of our N-PCR were quite low (27.3\% and $84 \%$, respectively) compared to Vaidya et al. [3] who reported $84.2 \%$ sensitivity and $100 \%$ specificity for their PCR against IFA. However, their subjects were women with abortion, whereas our participants were healthy animal handlers. Sensitivity of PCR/IFA depends on the time of collection of blood. PCR detects $C$. burnetii DNA in early stage after the onset of clinical symptoms, usually during the first 3 weeks before seroconversion. According to Schneeberger et al., PCR becomes negative after the appearance of antibodies [24]. Phase II antibodies (IgM and/or $\operatorname{IgG}$ ) are more predominant in early stage of the disease $[1,24]$. Phase II IgM antibodies may appear during 10-17 days of acute febrile illness, with simultaneous detection of Phase II IgG antibodies. IgM Phase II may be present even up to 1 year and IgG Phase II could be detected even for much longer period [1]. Hence, assessing the performance of molecular tests keeping the gold standard serological test, IFA is questionable since these are two 
entirely different parameters. Simultaneous detection of $C$. burnetii DNA and Phase II $\operatorname{IgG}$ antibodies may probably due to repeated exposure to infected livestock.

Trans-PCR targets the highly sensitive and specific gene IS1111, a transposase repetitive gene element. It is a multicopy genome, which is present in C. burnetii. It is highly helpful in the identification of C. burnetii DNA in different clinical specimens. This trans-PCR is essential to identify the positive samples, purify them, and perform gene sequencing, which ultimately will help in the construction of phylogenetic tree construction. Phylogenetic analysis of IS1111 gene of our study isolates shows maximal identity of $99 \%$ with the reference isolates, particularly from Bengaluru, Brazil, Colombia, France, and Iran.

To the best of our knowledge, animal handlers were not specifically examined for $C$. burnetii antibodies in India so far. This preliminary study was aimed at screening the animal handlers for QF with single but not paired serum samples. The mere presence of $C$. burnetii antibodies, without any clinical symptoms of $\mathrm{QF}$ does not require antibiotic treatment [1]. Now with current evidence of prior exposure to $C$. burnetii in 21 animal handlers, further elaborate work is warranted, by extending the study to include a larger population. Both clinical and laboratory investigations of these occupational exposures are to be carried out in long term. Animal handlers should be educated to prevent the infection by means of using protective clothing and proper disposal of animal waste is needed.

\section{Conclusion}

In spite of occupational hazards for animal handlers to $C$. burnetii, the awareness among them is minimal. We have provided retrospective evidence of QF in population of Puducherry. Further research is therefore needed to study the extent of this zoonosis in animal handlers of Puducherry.

\section{Authors' Contributions}

SS, BS, JP, and PXA planned, designed, and conducted the study. BS and JP performed sample collection. JP, PP, SS, BS, and PXA carried out data analysis. SA and JP performed the phylogenetic analysis. SS and PP drafted and revised the manuscript. All authors read and approved the final manuscript.

\section{Acknowledgments}

Corresponding author (SS) is thankful to the Indian Council of Medical Research for providing research grant for this Rickettsial Project (Iris id no: 2008-08180; File no - 30/3/41/2008/ECD-II) and also express sincere gratitude to the Chairman, ViceChancellor, Dean of Faculty, and Dean (Research), SBV. Dean (Faculty of Medicine) Mahatma Gandhi Medical College and Research Institute, Puducherry, India for their encouragement and financial support provided for this Faculty Research Project under Sri Balaji Vidyapeeth (Deemed to be University).

\section{Competing Interests}

The authors declare that they have no competing interests.

\section{Publisher's Note}

Veterinary World remains neutral with regard to jurisdictional claims in published institutional affiliation.

\section{References}

1. Anderson, A., Bijlmer, H., Fournier, P.E., Graves, S., Hartzell, J., Kersh, G.J., Limonard, G., Marrie, T.J., Massung, R.F., McQuiston, J.H., Nicholson, W.L., Paddock, C.D. and Sexton, D.J. (2013) Diagnosis and management of Q fever United States, 2013: Recommendations from CDC and the $\mathrm{Q}$ fever working group. MMWR Recomm. Rep., 62(RR-03): 1-30.

2. World Organization for Animal Health. (2013) Manual of Diagnostic Tests and Vaccines for Terrestrial Animals. Available from: http://www.oie.int/international-standardsetting/terrestrial-manual/Access-online. Retrieved on 13-06-2016.

3. Vaidya, V.M., Malik, S.V.S., Kaur, S., Kumar, S. and Barbuddhe, S.B. (2008) Comparison of PCR, immunofluorescence assay, and pathogen isolation for diagnosis of Q fever in humans with spontaneous abortions. J. Clin. Microbiol., 46(6): 2038-2044.

4. Khalili, M., Mosavi, M., Diali, H.G. and Mirza, H.N. (2014) Serologic survey for Coxiella burnetii phase II antibodies among slaughterhouse workers in Kerman, southeast of Iran. Asian Pac. J. Trop. Biomed., 4(Suppl 1): S209-S212.

5. Szymanska-Czerwinska, M., Galinska, E.M., Niemczuk, K. and Knap, J.P. (2015) Prevalence of Coxiella burnetii infection in humans occupationally exposed to animals in Poland. Vector Borne Zoonotic Dis., 15(4): 261-267.

6. Whitney, E.A., Massung, R.F., Candee, A.J., Ailes, E.C., Myers, L.M., Patterson, N.E. and Berkelman, R.L. (2009) Seroepidemiologic and occupational risk survey for Coxiella burnetii antibodies among US veterinarians. Clin. Infect. Dis., 48(5): 550-557.

7. Wielders, C.C., Boerman, A.W., Schimmer, B., van den Brom, R., Notermans, D.W., van der Hoek, W. and Schneeberger, P.M. (2015) Persistent high IgG phase I antibody levels against Coxiella burnetii among veterinarians compared to patients previously diagnosed with acute $\mathrm{Q}$ fever after three years of follow-up. PLoS One, 10(1): e0116937.

8. Kargar, M., Rashidi, A., Doosti, A., Najafi, A. and GhorbaniDalini, S. (2015) The sensitivity of the PCR method for detection of Coxiella burnetii in the milk samples. Zahedan J. Res. Med. Sci., 17(6): 29-32.

9. Park, J.H., Hwang, S.D., Acharya, D., Lee, S.H., Hwang, K.J., Yoo, S.J. and Lee, K. (2018) Sero-reactivity and risk factors associated with Coxiella burnetii infection among cattle slaughterhouse workers in South Korea. Int. J. Environ. Res. Public Health, 15(10): 2264-2273.

10. Sun, W.W., Cong, W., Li, M.H., Wang, C.F., Shan, X.F. and Qian, A.D. (2016) Coxiella burnetii seroprevalence and risk factors in cattle farmers and farm residents in three NorthEastern provinces and inner Mongolia autonomous region, China. Biomed. Res. Int., 2016(7059196): 1-7.

11. Akbarian, Z., Ziay, G., Schauwers, W., Noormal, B., Saeed, I., Qanee, A.H., Shahab, Z., Dennison, T., Dohoo, I. and Jackson, R. (2015) Brucellosis and Coxiella burnetii Infection in householders and their animals in secure villages in Herat province, Afghanistan: A cross-sectional 
study. PLoS Negl. Trop. Dis., 9(10): e0004112.

12. Vaidya, V.M., Malik, S.V.S., Bhilegaonkar, K.N., Rathore, R.S., Kaur, S. and Barbuddhe, S.B. (2010) Prevalence of Q fever in domestic animals with reproductive disorders. Comp. Immunol. Microbiol. Infect. Dis., 33(4): 307-321.

13. Das, D.P., Malik, S.V.S., Rawool, D.B., Das, S., Shoukat, S., Gandham, R.K., Saxena, S., Singh, R., Doijad, S.P. and Barbuddhe, S.B. (2014) Isolation of Coxiella burnetii from bovines with history of reproductive disorders in India and phylogenetic inference based on the partial sequencing of IS1111 element. Infect. Genet. Evol., 22(1): 67-71.

14. Rajagunalan, S., Gururaj, K., Lakshmikantan, U., Murugan, M., Ganesan, A., Sundar, A., Sureshkannan, S., Andani, D. and Pawaiya, R.S. (2019) Detection of the presence of Coxiella burnetii in a case of goat abortion: The first report from India. Trop. Anim. Health Prod., 51(4): 983-986.

15. Pradeep, J., Stephen, S., Pooja, P., Akshayavardhini, A., Sangeetha, B. and Antony, P.X. (2017) Coxiellosis in domestic livestock of Puducherry and Tamil Nadu: Detection of Coxiella burnetii DNA by polymerase chain reaction in slaughtered ruminants. Vet. World, 10(6): 667-671.

16. Sahu, R., Kale, S.B., Vergis, J., Dhaka, P., Kumar, M., Choudhary, M., Jain, L., Choudhary, B.K., Rawool, D.B., Chaudhari, S.P., Kurkure, N.V., Malik, S.V.S. and Barbuddhe, S.B. (2018) Apparent prevalence and risk factors associated with occurrence of Coxiella burnetii infection in goats and humans in Chhattisgarh and Odisha, India. Comp. Immunol. Microbiol. Infect. Dis., 60(3): 46-51.

17. Gangoliya, S.R., Kumar, S., Alam, S.I., Devi, D.R.G. and Guchhait, P. (2016) First molecular evidence of Coxiella burnetii in patients with atypical pneumonia, India. J. Med.
Microbiol., 65(3): 255-256.

18. Pradeep, J., Stephen, S., Sangeetha, B. and Antony, P.X. (2016) Seroprevalence of Bovine coxiellosis in Puducherry and Tamil Nadu with a note on its relevance to human Q fever. Biomedicine, 36(3): 51-54.

19. Stephen, S., Ambroise, S., Pradeep, J., Gunasekaran, D., Sangeetha, B. and Sarangapani, K. (2017) Unreliability of three commercial Coxiella burnetii phase II IgM ELISA kits for the seroscreening of acute $\mathrm{Q}$ fever in human cases. Indian J. Med. Res., 146(3): 386-391.

20. Lorenz, H., Jager, C., Willems, H. and Balger, G. (1998) PCR detection of Coxiella burnetii from different clinical specimens, especially bovine milk on the basis of DNA preparation with silica matrix. Appl. Environ. Microbiol., 64(11): 4234-4237.

21. Kumar, S., Stecher, G., Li, M., Knyaz, C. and Tamura, K. (2018) MEGA X: Molecular evolutionary genetics analysis across computing platforms. Mol. Biol. Evol., 35(6): 1547-1549.

22. Tamura, K. and Nei, M. (1993) Estimation of the number of nucleotide substitutions in the control region of mitochondrial DNA in humans and chimpanzees. Mol. Biol. Evol., 10(3): 512-526.

23. Jager, M.M., Weers-Pothoff, G., Hermans, M.H.A., Meekelenkamp, J.C.E., Schellekens, J.J.A., Renders, N.H.M., Leenders, A.C.A., Schneeberger, P.M. and Wever, P.C. (2011) Evaluation of diagnostic algorithm for acute $\mathrm{Q}$ fever in an outbreak setting. Clin. Vaccine Immunol., 18(6): 963-968.

24. Schneeberger, P.M., Hermans, M.H., van Hannen, E.J., Schellekens, J.J., Leenders, A.C. and Wever, P.C. (2010) Real-time PCR with serum samples is indispensable for early diagnosis of acute Q fever. Clin. Vaccine Immunol., 17(2): 286-290. 